\section{Demonstration of Basic Proteins That Bind Retinoic Acid in the Human Myeloid Leukemia Cell Line HL60}

\author{
Noriko TAKAHASHI* and Toshihiro OHBA \\ Laboratory of Physiological Chemistry, Institute of Medicinal \\ Chemistry, Hoshi University; Shinagawa, Tokyo 142-8501, Japan. \\ Received July 15, 2009; accepted August 29, 2009; published \\ online September 2, 2009
}

Retinoic acid (RA) has a variety of biological effects in mammalian cells and tissues. It is well known that RA is a potent anticancer agent that induces differentiation of leukemia cells as well as inhibiting cell growth. The current study examined HL60 proteins using anti-RA monoclonal antibodies (ARMAs) and found that some RA-binding proteins may be histones. These proteins eluted in the void volume fractions following Mono $Q$ anion exchange chromatography and immunostained with ARMAs. These ARMAs showed specific binding to the proteins in a saturable manner that depended on antibody concentration. Certain of these proteins co-migrated with histones on one-dimensional polyacrylamide gel electrophoresis. It was also found that histones isolated from HL60 cells treated with RA also immunostained with ARMAs. These results indicate that basic proteins, including histones, may be bound to RA covalently in HL60 cells and that RA-binding histones may play significant roles in the transcriptional regulation of genes by RA.

Key words retinoic acid-binding protein; basic protein; retinoic acid; HL60; post-translational modification

Retinoic acid (RA), a carboxylic acid derivative of vitamin-A (retinol), serves numerous roles in the physiology and biochemistry of mammalian cells and tissues. RA supports growth in animals, maintains epithelial tissues and bone, and plays a crucial role in spermatogenesis and reproduction. ${ }^{1)}$ Underscoring the importance of RA, is its potent induction of differentiation of certain cell types as well as its utility in the treatment of patients with various malignancies, especially human acute promylocytic leukaemia. ${ }^{2)}$ In light of the known biological effects of RA, clarifying mechanisms of RA action is of critically important.

The mechanisms beyond the effects of RA on HL60 cells as well as on other cells have not been fully elucidated. One mechanism of RA action in cell development and differentiation involves RA nuclear receptors (RARs and retinoid X receptors). ${ }^{1,3-6)}$ These directly regulate (activate or repress) transcription of target genes by binding to specific DNA sequences. Another mechanism by which RA may act on cells is retinoylation (acylation of proteins by RA). ${ }^{7-13)}$ Retinoylation is one of a large number of diverse modifications affecting proteins that include phosphorylation, palmitoylation and myristoylation. In HL60 cells, the dose-response curves for RA-induced differentiation and retinoylation are similar, and with positive correlation. ${ }^{8,11)}$ Furthermore, the regulatory subunits of cyclic AMP-dependent protein kinase type I and type II (RI $\alpha$ and $\mathrm{RII} \alpha$ ) and vimentin are also retinoylated. ${ }^{9,12)}$ Metabolic pathways for retinoylation involve the formation of a retinoyl-CoA intermediate ${ }^{14,15)}$ with subsequent transfer of the retinoyl moiety to protein. ${ }^{16)}$ This is similar to palmitoylation and myristoylation, ${ }^{17,18)}$ which also occur via the formation of CoA derivatives. The ATPdependent generation of retinoyl-CoA occurs in cells and tissues and this may play a significant physiological role in RA actions mediated by retinoylation. ${ }^{14,15)}$

Previous studies have shown that anti-RA monoclonal antibodies (ARMAs) exhibit specificity against RA. ${ }^{19-24)}$ These ARMAs have been used to study the distribution of retinoids in the chick limb bud, ${ }^{19)}$ in early quail embryos ${ }^{21)}$ and in human premalignant oral lesions. ${ }^{22}$ In addition, they have been utilized to neutralize endogenous $\mathrm{RA}^{23)}$ and identify RA-binding proteins. ${ }^{24)}$ In the current study, we demonstrate that ARMAs bind to basic proteins, in particular histones.

\section{MATERIALS AND METHODS}

Cells Human myeloid leukemia HL60 cells were maintained in serum-containing medium (GIBCO BRL, Gaithersburg, MD, U.S.A.) consisting of RPMI 1640 supplemented with $10 \mathrm{~mm}$ 4-(2-hydroxyethyl)-1-piperazinethanesulfonic acid (HEPES), $\mathrm{pH} 7.3$ and 10\% (v/v) fetal bovine serum (FBS) (GIBCO). Cell cultures were incubated at $37^{\circ} \mathrm{C}$ in a humidified atmosphere of $5 \% \mathrm{CO}_{2}$ in air. Cell number was determined with an electronic particle counter (BeckmanCoulter, Hialeah, FL, U.S.A.) and cell viability was assessed by trypan blue dye exclusion.

Preparation of Subcellular Fractions of HL60 Cells Incorporated with RA Exponentially growing cells were harvested by centrifugation and resuspended at a concentration of $2 \times 10^{6}$ cells $/ \mathrm{ml}$ in serum-free medium consisting of RPMI 1640 supplemented with 10 mm HEPES, pH 7.3, $5 \mu \mathrm{g}$ of insulin $/ \mathrm{ml}$, and $5 \mu \mathrm{g}$ of transferrin $/ \mathrm{ml}$. The concentration of RA and conditions used were the same as those previously reported to induce retinoylation. ${ }^{8,9)}$ Cells were incubated with $100 \mathrm{~nm}$ RA for $24 \mathrm{~h}$, harvested by centrifugation $(200 \times \boldsymbol{g}$, $10 \mathrm{~min}$ ) and washed with phosphate-buffered saline (PBS; $1.5 \mathrm{~mm} \mathrm{KH}_{2} \mathrm{PO}_{4}, 8.1 \mathrm{~mm} \mathrm{Na}_{2} \mathrm{HPO}_{4}, 136.9 \mathrm{~mm} \mathrm{NaCl}, \mathrm{pH} 7.2$ ). Cells $\left(6.6 \times 10^{8}\right.$ cells) were resuspended with $2 \mathrm{ml}$ of Buffer A [10 mm Tris- $\mathrm{HCl}$ buffer (pH 7.5), 0.005\% (v/v) Tween 20 and $1.5 \mathrm{~mm}$ phenylmethylsulfonyl fluoride (PMSF)], and then homogenized by Ultra-Turrax (IKA-Analysentechnik $\mathrm{GmbH}$, Heitersheim, Germany). After centrifugation of homogenates $(100000 \times \boldsymbol{g}, 60 \mathrm{~min})$, the resulting supernatant was used as the soluble extract. The precipitated fraction was dissolved with Buffer A supplemented with 10\% (w/v) 3-(3-cholamidopropyl)dimethylammonio-1-propanesulfonate (CHAPS) and homogenized by Ultra-Turrax. After centrifugation $(100000 \times \boldsymbol{g}, 60 \mathrm{~min})$, the resulting supernatant was used as the insoluble extract. Subcellular fractions were divided into tubes and stored at $-80^{\circ} \mathrm{C}$ so as not to freeze-thaw. Storage was no longer than 2 months prior to use.

Chromatographic Separation of Proteins in Soluble and Insoluble Extracts of HL60 Cells Soluble and insoluble extracts prepared as described above were applied to Mono Q columns $(5 \times 50 \mathrm{~mm}$, Pharmacia LKB) equilibrated with Buffer B [20 mM potassium phosphate buffer ( $\mathrm{pH} 6.8)$, $1 \mathrm{~mm}$ EDTA, and $2 \mathrm{~mm}$ 2-mercaptoethanol]. The columns were washed with $5 \mathrm{ml}$ of Buffer B and then eluted with a gradient of 0 to $0.5 \mathrm{M} \mathrm{NaCl}$ in Buffer B. Fractions of $1 \mathrm{ml}$ 
were collected at a flow rate of $0.5 \mathrm{ml} / \mathrm{min}$.

Isolation of Histones from HL60 Cells Cells $\left(2 \times 10^{6}\right.$ cells $/ \mathrm{ml}, 5 \mathrm{ml}$ ) were incubated with or without $100 \mathrm{~nm}$ RA as described above and harvested by centrifugation $(200 \times \boldsymbol{g}$, $10 \mathrm{~min})$. Cells $\left(1.0-2.0 \times 10^{7}\right.$ cells $)$ were suspended with $10-15$ volume of PBS and centrifuged $(200 \times \boldsymbol{g}, 10 \mathrm{~min})$. Cells were resuspended with 5-10 volume of Lysis Buffer supplemented with $10 \mathrm{~mm}$ HEPES, pH 7.9, $1.5 \mathrm{~mm} \mathrm{MgCl}_{2}$, $10 \mathrm{~mm} \mathrm{KCl,} 0.5 \mathrm{~mm}$ dithiothreitol, and $1.5 \mathrm{~mm}$ PMSF. Sulfuric acid was added to a final concentration of $0.2 \mathrm{M}$, and the mixtures were incubated on ice for $30 \mathrm{~min}$. After centrifugation $(10080 \times \boldsymbol{g}, 10 \mathrm{~min})$, the supernatant containing acid-soluble proteins was dialyzed against $0.1 \mathrm{M}$ acetic acid $(200 \mathrm{ml})$ twice at $1-2 \mathrm{~h}$ per dialysis, and then dialyzed three times against $\mathrm{H}_{2} \mathrm{O}(200 \mathrm{ml})$ for $1 \mathrm{~h}, 3 \mathrm{~h}$, and overnight, respectively. Protein content was measured using the Bicinchoninic Acid (BCA) Protein Assay (Piece, Rockford, IL, U.S.A.) and stored at $-80^{\circ} \mathrm{C}$.

Immunostaining One-dimensional polyacrylamide gel electrophoresis (1D-PAGE) was performed according to Laemmli's method. ${ }^{25}$ ) Briefly, sample solutions were heated at $100{ }^{\circ} \mathrm{C}$ for $5-10 \mathrm{~min}$, then electrophoresis on $12.5 \%$ or $15 \%$ polyacrylamide gels $(1.0 \mathrm{~mm}$ thick) was performed. Proteins separated by 1D-PAGE were transferred to a polyvinylidene difluoride (PVDF, Millipore Co., U.S.A.) membrane using an electroblotter (Bio Craft, Japan). Antigen reactivity with core histone antibody (abcam, Cambridgeshire, U.K.) or ARMAs ${ }^{24)}$ was visualized using chemiluminescence staining by the Western blotting starter Kit (ECL plus, Amersham Bioscience Co., U.S.A.) according to the manufacturer's instructions. Gels were fixed and stained with Coomassie Brilliant Blue R-250 (CBB). Molecular weight (Mr) markers were from GIBCO BRL.

\section{RESULTS}

RA-Binding Proteins in Void Fractions Following Anion Exchange Chromatography HL60 cells treated with $100 \mathrm{~nm}$ RA were initially fractionated into soluble and insoluble extracts. Each extract was subjected to Mono Q anion exchange chromatography and proteins were eluted using a gradient of 0 to $0.5 \mathrm{M} \mathrm{NaCl}$. The elution patterns of proteins from soluble and insoluble extracts are shown in Figs. 1A and C. Significant levels of protein were observed in the void volume (fractions 2, 3) following Mono Q column chromatography. The current study focused on basic proteins having cationic charges in the void fractions that might bind to RA. In general, the separation of basic proteins by $1 \mathrm{D}-\mathrm{PAGE}$ depends on protein charge, but not on molecular weight. Basic proteins are not separated by 2D-PAGE, because only proteins exhibiting $\mathrm{p} I$ values of $3.5-10$ can be separated by this technique. In order to verify RA-binding proteins, cellular proteins in void fractions were separated by 1D-PAGE (12.5\%), then ARMA immunoblot analysis was performed.

In the soluble extracts, more than twelve RA-binding proteins were observed in fractions 2 and 3 (Fig. 1B). A major RA-binding protein in fraction 2 exhibited a molecular weight of approximately $40 \mathrm{~K}$. Other RA-binding proteins found from the top to the bottom of blot respectively were at positions corresponding to molecular weights ranging from
(A)

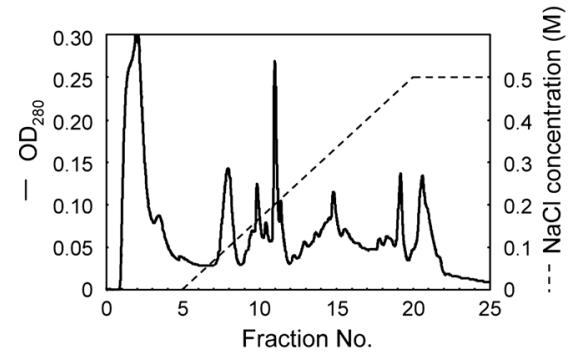

(C)

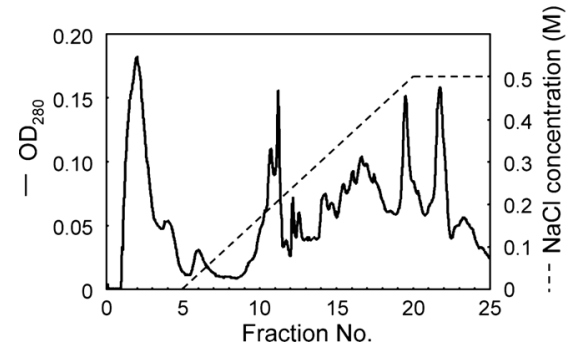

(B)

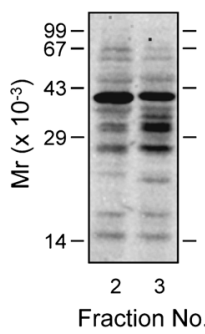

(D)

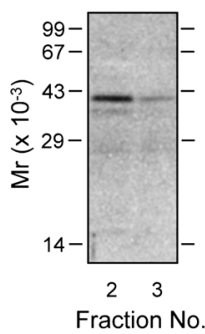

Fig. 1. Anion-Exchange Chromatography of Proteins in Soluble and Insoluble Extracts of HL60 Cells Followed by Immunostaining with ARMAs

HL60 cells grown in serum-free medium were harvested by centrifugation and homogenized. Soluble (A, B) and insoluble (C, D) cell extracts were prepared as described under Materials and Methods and chromatographed on Mono Q columns. Proteins $(10 \mu \mathrm{l})$ in $1 \mathrm{ml}$-column void fractions were separated by 1D-PAGE $(12.5 \%)$ and analyzed by immunostaining with ARMAs (dilution, 1/100) (B, D).

65 to $15 \mathrm{~K}$. In contrast, the amounts of RA-binding proteins in the insoluble fractions were significantly less than those in the soluble fractions (Fig. 1D). Only four RA-binding proteins were observed in fraction 2 at positions corresponding to approximately $\mathrm{Mr} 40,37,28$, and $15 \mathrm{~K}$. Proteins in Mono Q fractions 2 and 3 that were prepared from the HL60 cells treated without $100 \mathrm{~nm}$ RA, were not detected by ARMAs (data not shown). These results indicate that RA binding occurs with extremely basic (cationic) proteins that elute to a greater extent in the void volume of the soluble extract than in the insoluble extract, although both extracts contain RAbinding proteins that exhibit the same molecular weights.

Reactivity of ARMAs with RA-Binding Protein in Void Volume Fractions The RA-binding proteins in fractions 2, 3 , and 17 were examined by immunostaining using two concentrations of ARMAs. Figure 2 shows 1D-PAGE (12.5\%) patterns of ARMA-binding proteins in the soluble extracts. A RA-binding protein in fractions 2 and 3 corresponding to a molecular weight of approximately $40 \mathrm{~K}$ was observed at two ARMA dilutions (A: 1/100, B: 1/1000), while density was reduced in the order of A and B (Fig. 2). Similar results were seen for fraction 17 (Fig. 2). The densities of bands decreased in parallel with decreasing concentrations of proteins. In addition, RA-binding proteins were not detected when ARMAs were added with RA in advance. These results indicate that ARMAs specifically recognize RA bound to proteins.

Comparison of 1D-PAGE Patterns of Proteins Detected by ARMAs and Histone Antibodies It was found that several proteins in the void volume fractions from Mono Q column chromatography reacted with ARMAs (Fig. 1) and that the binding of ARMAs with these proteins was specific (Fig. 2). These results suggest that void volume fractions 
(A)

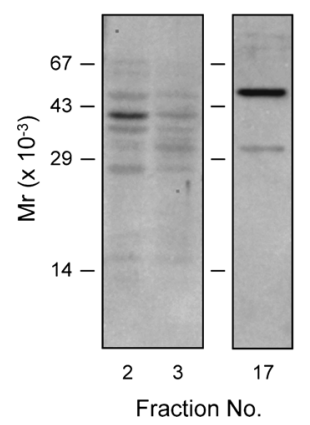

(B)

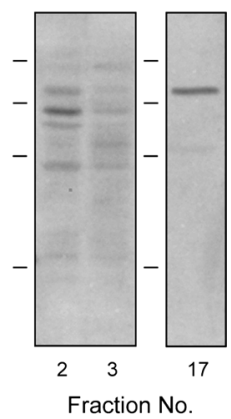

Fig. 2. Specificity of ARMAs

Protein $(5 \mu 1)$ from soluble extracts in fractions 2 and $3(1 \mathrm{ml})$ shown in Fig. 1A were separated by 1 D-PAGE (12.5\%) and analyzed by immunostaining with ARMAs (dilution; A, 1/100; B, 1/1000) as described under Materials and Methods.
(A)

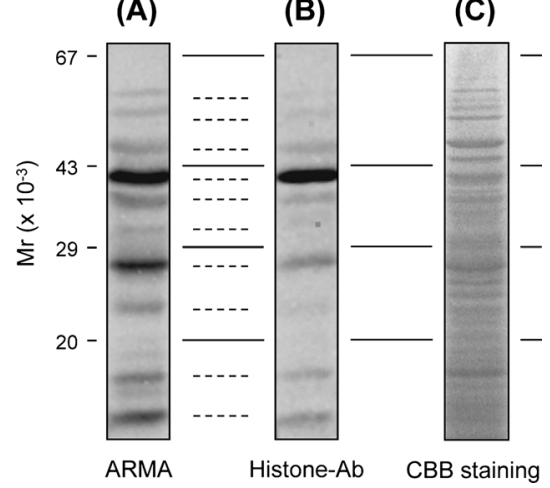

Fig. 3. Identification of RA-Binding Proteins in Fraction 2 by the Comparison of 1D-PAGE Patterns after Immunostaining Using ARMAs and Histone Antibodies

Protein $(10 \mu \mathrm{l})$ in fractions $2(1 \mathrm{ml})$ of soluble extract shown in Fig. 1A were separated by 1 D-PAGE (15\%) and analyzed by immunostaining with (A) ARMAs (dilution; $1 / 100)$ and (B) histone antibodies (dilution; 1/1000) or by staining proteins with $(\mathrm{C})$ $\mathrm{CBB}$ as described under Materials and Methods.

contain RA-binding proteins and basic proteins, and that basic proteins (e.g. histone proteins etc.) may be bound to RA. Initially we compared 1D-PAGE patterns of proteins in fraction 2 as determined by immunostaining with ARMAs and histone antibodies. It is well known that molecular weights of histones fall between approximately $10-20 \mathrm{~K}$ and that histones are separated by 1D-PAGE in a molecular weight-independent manner. ${ }^{26)}$

Proteins in fraction 2 separated by 1D-PAGE (15\%) were transferred to a membrane and visualized by reacting with ARMAs and histone antibodies. Proteins in the gel were also stained with $\mathrm{CBB}$. The patterns of proteins immunostained by ARMAs (Fig. 3A) and by histone antibodies (Fig. 3B) were identical, and most of these proteins were major components of fraction 2 (Fig. 3C). In the absence of primary antibodies, no bands were seen on the membrane. These results strongly suggest that histones might be bound to RA.

ARMAs React with Histones Isolated from HL60 Cells To confirm that histones bound to RA covalently, we isolated histones from HL60 cells that had been incubated with $100 \mathrm{~nm}$ RA for $24 \mathrm{~h}$. The histone proteins were separated by 1D-PAGE (15\%), and then analyzed by either CBB staining or by immunostaining with ARMAs. As shown in Fig. 4A, several protein bands were observed after CBB staining. Previous studies have already shown that these bands are, from

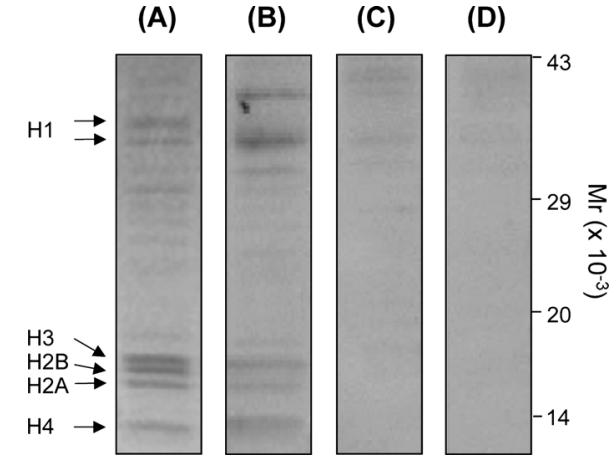

Fig. 4. Comparison of 1D-PAGE Patterns of Isolated Histones after Protein Staining and Immunostaining Using ARMAs

Histones isolated from HL60 cells grown in the presence (A, B, C) or absence (D) of RA were separated by 1D-PAGE $(15 \%)$, and immunostained with ARMAs (B, D) or ARMAs treated with 100 nм RA (C) (dilution; 1/100). Staining proteins with CBB (A) was conducted as described under Materials and Methods.

top to bottom respectively, Histone 1 ( $\mathrm{H} 1)$, Histone $3(\mathrm{H} 3)$, Histone 2B (H2B), Histone 2A (H2A), or Histone $4(\mathrm{H} 4) .{ }^{26)}$ These histone proteins immunostained with ARMAs (Fig. 4B). However, they were not detected with ARMAs when RA (100 nM) was added in advance to block the antigen recognition sites (Fig. 4C). Hisones prepared from the HL60 cells treated without $100 \mathrm{~nm}$ RA, were not detected by ARMAs (Fig. 4D). In addition, these ARMA-bound proteins were confirmed to be histones by using antibodies against histones. These results indicate that ARMAs bind to RA that is linked to histones and that histones are bound to RA. These results strongly suggest that histones bind to RA covalently.

\section{DISCUSSION}

The current study examined RA-binding proteins in void volume fractions of Mono $\mathrm{Q}$ chromatography that were detected by using ARMAs. It was found that RA might be bound to histones in HL60 cells (Figs. 1-4). When soluble and insoluble extracts prepared from HL60 cells were subjected to Mono Q chromatography (Fig. 1), certain proteins in the void volume fractions, including fractions 2 and 3 were immunostained with both ARMAs and histone antibodies that bound specifically (Figs. 2, 3). In addition, histones isolated from HL60 cells were detected by ARMAs (Fig. 4). In this study, we found that certain RA-binding proteins in HL60 cells may be histones. It is also noteworthy that basic (cationic) proteins other than histones were also found to bind to RA.

RA-binding proteins can be two species. One species is protein-bound to RA non-covalently with hydrogen bond and the other is bound to RA covalently. ARMAs can detect both species of RA-binding proteins. Recently, the detection of RA-binding proteins in HL60 cells using ARMAs was reported. $^{24)}$ The 2D-PAGE pattern of RA-binding proteins detected using ARMAs is almost identical to retinoylated proteins detected by conventional methods using radioactive $\left[{ }^{3} \mathrm{H}\right]-$ RA. Retinoylated proteins in HL60 cells previously identified by conventional methods include vimentin ${ }^{12)}$ and the regulatory subunits of cAMP-dependent protein kinase A. ${ }^{9)}$ These have also been detected by ARMAs. ${ }^{24)}$ Currently, we make a distinction between retinoylated proteins (RA acylation of proteins) identified using radioactive $\left[{ }^{3} \mathrm{H}\right]-\mathrm{RA}$ 
and RA-binding proteins (proteins modified by RA) identified by ARMAs. This is because a small possibility exists that not all proteins detected by ARMAs are completely consistent with retinoylated proteins. In the current study, histones appear to be bound to RA covalently. It would be interesting to investigate whether histones could be detected by conventional methods using radioactive $\left[{ }^{3} \mathrm{H}\right]-\mathrm{RA}$.

It is well known that a variety of protein modifications occur to histones, including acetylation, phosphorylation and methylation. ${ }^{26)}$ Recently, propionylation and butyrylation of histones has been reported. ${ }^{27)}$ Among posttranslational modifications of histones, acetylation is the most prominent mechanism by which cells regulate chromatin structure. Acetylation of histones disrupts nucleosomes and allows the DNA to become accessible to transcriptional machinery. Removal of acetyl groups allows the histones to bind more tightly to DNA and to maintain a transcriptionally repressed chromatin structure. Acetylation occurs by enzymes with histone acetylase (HAT) activity, while acetyl residues are removed by histone deacetylase (HDAC). Butyric acid, an inhibitor of deacetylase that results in increased histone acetylation, induces differentiation of HL60 cells to monocyte/ macrophage-like cells with inhibition of cell growth. In the current study, we have found that RA, which induces differentiation to granulocyte-like cells, may be bound to histones (Figs. 1-4). It would be interesting to examine whether histone binding into RA alters RA action, affecting the activation or repression of gene transcription as do other histone modifications, such as acetylation.

RAR is ligand-dependent transcriptional activator ${ }^{28)}$ that mediates chromatin remodeling. ${ }^{29)}$ Binding of ligand to RAR initiates a conformational change in the $C$-terminus of RAR, which contains the binding site of $N$-CoR (a nuclear corepressor). ${ }^{30-32)}$ Ligand-locked RARs bind to coactivator complexes and activate transcription. Thus, recruitment of the coactivator complex (p300, pCAF, $N$-CoA) brings HAT into proximity with the promoter to which RAR binds, leading to the acetylation of histones. In this study, histones were found to bind to RA. Further studies are under investigation to elucidate the effects on gene transcription of RA-binding histones and RARs. In the current study, it has been newly found that histones bound to RA. These findings may lead to a clarification of new mechanisms of RA action.

Acknowledgments We thank Dr. Terrence Burke, Jr. and Dr. Kiyoe Ura for helpful comments. This investigation was supported in part by Sankyo Foundation of Life Science, the Ministry of Education, Culture, Sports, Science and Technol- ogy of Japan and the Open Research Center Project.

\section{REFERENCES}

1) Kastner P., Mark M., Chambon P., Cell, 83, 859-869 (1995).

2) Huang M. E., Ye Y. C., Chen S. R., Chai J. R., Lu J. X., Zhoa L., Gu L. J., Wang Z. Y., Blood, 72, 567-572 (1988).

3) Mangelsdorf D. J., Evans R. M., Cell, 83, 841-850 (1995).

4) Chambon P., FASEB J., 10, 940-954 (1996).

5) Rowe A., Int. J. Biochem. Cell Biol., 29, 275-278 (1997).

6) Wolf G., Nutr. Rev., 58, 151-153 (2000).

7) Takahashi N., Breitman T. R., In Vitro Cell Dev. Biol., 25, 1199-1200 (1989).

8) Takahashi N., Breitman T. R., J. Biol. Chem., 264, 5159-5163 (1989).

9) Takahashi N., Liapi C., Anderson W. B., Breitman T. R., Arch. Biochem. Biophys., 290, 293-302 (1991).

10) Takahashi N., Jetten A. M., Breitman T. R., Biochem. Biophys. Res. Commun., 180, 393-400 (1991).

11) Takahashi N., Breitman T. R., Arch. Biochem. Biophys., 285, 105110 (1991).

12) Takahashi N., Breitman T. R., J. Biol. Chem., 269, 5913-5917 (1994).

13) Takahashi N., Breitman T. R., Methods Enzymol., 189, 233-238 (1990).

14) Wada M., Fukui T., Kubo Y., Takahashi N., J. Biochem. (Tokyo), 130, $457-463$ (2001).

15) Renstrom B., DeLuca H. F., Biochim. Biophys. Acta, 998, 69-74 (1989).

16) Kubo Y., Wada M., Ohba T., Takahashi N., J. Biochem. (Tokyo), 138, 493-500 (2005).

17) Schultz A. M., Henderson L. E., Oroszlan S., Annu. Rev. Cell Biol., 4, 611-647 (1988).

18) Towler D. A., Gordon J. I., Adams S. P., Glaser L., Annu. Rev. Biochem., 57, 69-99 (1988).

19) Tamura K., Ohsugi K., Ide H., Dev. Biol., 140, 20-26 (1990).

20) Zhou H. R., Abouzied M. M., Zile M. H., J. Immunol. Methods, 138, $211-223(1991)$

21) Twal W., Roze L., Zile M. H., Dev. Biol., 168, 225-234 (1995).

22) Xu X. C., Zile M. H., Lippman S. M., Lee J. S., Lee J. J., Hong W. K., Lotan R., Cancer Res., 55, 5507-5511 (1995).

23) Pain B., Clark M. E., Shen M., Nakazawa H., Sakurai M., Samarut J., Etches R. J., Development, 122, 2339-2348 (1996).

24) Kubo Y., Ohba T., Takahashi N., J. Biochem., 144, 349-355 (2008).

25) Laemmli U. K., Nature (London), 227, 680—685 (1970).

26) Wolffe A., "Chromatin: Structure and Function," Academic Press, San Diego, 1998.

27) Chen Y., Sprung R., Tang Y., Ball H., Sangras B., Kim S. C., Falck J. R., Peng J., Gu W., Zhao Y., Mol. Cell Proteomics, 6, 812-819 (2007).

28) Evans R. M., FEBS Lett., 234, 73-78 (1988).

29) Glass C. K., Rose D. W., Rosenfeld M. G., Curr. Opin. Cell Biol., 9, 222-232 (1997).

30) Driscoll J. E., Seachord C. L., Lupisella J. A., Darveau R. P., Reczek P. R., J. Biol. Chem., 271, 22969-22975 (1996).

31) Heery D. M., Kalkhoven E., Hoare S., Parker M. G., Nature (London), 387, 733 -736 (1997).

32) Lin B. C., Hong S. H., Krig S., Yoh S. M., Privalsky M. L., Mol. Cell. Biol., 17, 6131-6138 (1997). 